\title{
INTERNACIONALIZAÇÃO DE MICRO, PEQUENAS E MÉDIAS EMPRESAS INOVADORAS NO BRASIL Desafios do novo paradigma de desenvolvimento
}

\section{Sonia Karam Guimarães}

Universidade Federal do Rio Grande do Sul (UFRGS), Porto Alegre - RS, Brasil. E-mail: sonia21@ufrgs.br.

\section{Lucas Rodrigues Azambuja}

Ibmec, Belo Horizonte - MG, Brasil. E-mail: lucas.azambuja@ibmec.edu.br.

DOI: $10.1590 / 339708 / 2018$

\section{Introdução}

Um dos pressupostos econômicos mais relevantes na atualidade é o de que o desenvolvimento econômico depende de uma integração qualificada à economia mundial. Duas questôes relevantes compóem esse pressuposto: abertura ao mercado mundial e inovação. No passado, a internacionalização estava restrita às grandes empresas; hoje, micro, pequenas e médias empresas (MPMEs) envolvem-se crescentemente no mercado global, não apenas por meio de intercâmbio comercial, mas também de parcerias, oferta de serviços pós-venda, criação de franquias, entre outras atividades. Porém, para ser bem-sucedidas em mercados estrangeiros, é necessário que as MPMEs apresen- tem vantagens competitivas baseadas em inovação, complexidade e/ou sofisticação dos produtos e serviços oferecidos, isto é, sejam MPMEs inovadoras ou intensivas em conhecimento.

A internacionalização de MPMEs inovadoras e/ ou intensivas em conhecimento cresceu significativamente - em razão da globalização e da difusão de novas tecnologias -, adquirindo relevância mundial nas últimas décadas, tornando o fenômeno uma área de interesse acadêmico, conforme demonstrado por publicaçóes científicas como o Journal of International Studies, que passou a dedicar espaço para o "empreendedorismo internacional", e o periódico Journal of International Entrepreneurship, especializado no assunto, apenas para citar dois exemplos.

O crescimento desse fenômeno resulta da emergência de um novo paradigma que configura a chamada nova economia, em que conhecimento e inovação são considerados uma vantagem comparativa por excelência e, portanto, motor da economia. 
Tais MPMEs assumem um novo papel ao ser reconhecidas como fator impulsionador da atividade inovadora e, dessa forma, são consideradas a verdadeira novidade do capitalismo atual (Johnson, 2004; Rialp et al.,2005; Zahra, 2005; Ruzzier et al., 2006; Saxenian e Sabel, 2008; Whittaker, 2009).

O tema constitui área de interesse, considerando-se que a internacionalização tende a qualificar as empresas envolvidas, criando possibilidades para a transferência de tecnologias e para o desenvolvimento de capacidades para a criação de valor, fatores que contribuem para dinamizar a economia. A sociologia poderá contribuir de maneira relevante para melhor compreensão do fenômeno, ao ir além da análise sobre os condicionantes econômicos e assim revelar a importância de fatores sociais, políticos e culturais na sua definição.

Neste artigo, o foco encontra-se em uma dimensão do contexto da nova economia, a saber, a internacionalização de MPMEs no Brasil, onde esse processo vem ocorrendo timidamente.

Rialp et al. (2005) chamam a atenção para o fato de que as formulaçóes teóricas acerca do crescimento da internacionalização de MPMEs inovadoras e/ou intensivas em conhecimento baseiam-se nas experiências de países como Estados Unidos, Austrália, Canadá, Suíça, Irlanda, Nova Zelândia, Grã-Bretanha, Alemanha, França, Espanha, Israel e países nórdicos. Os autores afirmam que futuras pesquisas deveriam ser feitas em países não desenvolvidos para confirmar que não há especificidade geográfica no fenômeno da internacionalizaçáo dessas empresas (Rialp et al., 2005, p. 156).

O estudo cujos resultados são apresentados neste artigo inspirou-se nessa afirmação e busca avaliar em que medida as particularidades da realidade econômica e político-cultural do Brasil se refletiriam na configuração do fenômeno investigado.

$\mathrm{O}$ artigo está dividido em duas partes: na primeira, realizam-se breves consideraçóes conceituais sobre o fenômeno em estudo - empreendedorismo internacional - e são mostradas as ações promovidas pelo Estado brasileiro na tentativa promover o catching up; na segunda, apresentam-se resultados da pesquisa que sugerem, ao final, algumas consideraçóes.

\section{Internacionalização e empreendedorismo internacional}

Internacionalização é um conceito geral que inclui diferentes atividades, desde exportação de produtos/serviços ou estabelecimento de joint ventures e subsidiárias no exterior, até contratação de empresas e outros tipos de arranjos, como cooperação entre empresas para desenvolvimento de atividades de P\&D (Pesquisa e Desenvolvimento). Neste estudo, utilizou-se o sentido geral do conceito, sem limitar as atividades econômicas internacionais a operaçóes comerciais, mas considerando os demais tipos referidos de relações entre empresas.

A internacionalização beneficia as empresas: diversifica os mercados, favorece a aquisição de novos conhecimentos tecnológicos e estratégias de negócios, bem como impóe maior qualificação à produção e aos serviços, o que tende a estimular a inovação. Esses fatores atuam como fontes de vantagem competitiva para as empresas.

Destaca-se, na forma de internacionalização atual, o processo de descentralização e colaboração em atividades de $\mathrm{P} \& \mathrm{D}$, estimulado pelas novas tecnologias: de diferentes locais, independente da distância geográfica, observa-se a reunião de talentos, experts e compartilhamento de recursos, na busca de solução de problemas complexos.

Empreendedorismo internacional não é um fenômeno novo, a novidade está em seu crescimento e relevância recentes, como evidencia a extensa literatura sobre o tema "internacionalização de MPMEs inovadoras". ${ }^{1}$ No Brasil, no entanto, ele é praticamente ignorado ou aparece de forma modesta na área da sociologia, mas com potencial de aumento dessa abordagem.

No que se refere ao empreendedorismo, este é um conceito controverso, não sendo possível desenvolver os argumentos em torno da questáo no âmbito deste artigo. ${ }^{2}$ Considerando-se estudos sobre empreendedorismo internacional, identificam-se diferentes abordagens.

Nos anos de 1970, o processo de internacionalização foi concebido como um continuum (o chamado "modelo Uppsala"; Johanson e Vahlne, 1977), em que o deslocamento da empresa ocorreria gradualmente, do local ao regional e ao inter- 
nacional, após a consolidação no mercado doméstico. Essa abordagem considera a importância das distâncias cultural e geográfica: quanto menores, mais rápida e bem-sucedida seria a internacionalização (Kuemmerle, 2005). Tal perspectiva tem sido criticada por conceber o empreendedorismo internacional como um processo/ciclo que evolui de um estágio a outro, em resposta a estímulos, pressupondo que estímulos semelhantes produziriam respostas padronizadas. O contra-argumento é de que na era das tecnologias da informação e comunicação e da globalização, a trajetória internacional de uma empresa é menos suscetível às distâncias geográficas e culturais e tende a não seguir uma trajetória evolutiva (Johanson e Wiedersheim-Paul, 1975; Numella, Saarenketo e Puumalainen, 2004; Kuemmerle, 2005).

Quanto às abordagens atuais, encontram-se as que destacam aspectos estruturais ou, como alguns preferem denominar, forças habilitadoras da atualidade: por exemplo, menor custo e maior rapidez no transporte de pessoas e mercadorias (Oviatt e McDougall, 1999). Argumenta-se, em oposição, que os fatores estruturais necessitam de forças motivadoras, como oportunidades de exploração de novos mercados; incentivos públicos no país de origem; compartilhamento de conhecimentos e de custos de pesquisa; concorrentes nacionais internacionalizados; entrada de concorrentes estrangeiros no mercado doméstico. Nesse contexto, destaca-se a importância de instituiçóes facilitadoras que possibilitem intercâmbio sistemático de informações relevantes entre empreendedores e associaçóes empresariais, consultores, provedores de capital de risco e organizações científicas. O empreendedorismo internacional é, dessa forma, concebido como um processo coletivo (Kalantaridis, 2004 apud Herrmann, 2010). Nesse mesmo registro, a qualidade das instituições é reconhecida como fator decisivo, visto que influenciaria as decisóes sobre investimentos, organização da produção e estratégias e políticas de desenvolvimento.

Alguns autores consideram, contudo, que a existência dos fatores referidos não necessariamente garantiria o êxito do processo de internacionalização, pressupondo que características subjetivas do empreendedor (personalidade, valores, atitudes e comportamentos) é que definiriam a percepção e interpretação - favorável ou não - aos incentivos disponíveis, transformando-os (ou não) em tomadas de decisão (Voerman, 2003; Oviatt e McDougall, 2005).

Outras abordagens destacam a importância do "capital social" de que dispóe o empreendedor acesso à informação sobre oportunidades internacionais mediante conexôes e interações sociais, anteriores às transaçóes econômicas (experiência pessoal de vida, como educaçáo ou trabalho no exterior) -, o que resultaria em maior capacidade de identificar possibilidades estruturais e motivacionais para o desenvolvimento da internacionalização dos empreendimentos (Ferrary e Granovetter, 2009; Granovetter, 2000; Martinelli, 2009).

A abordagem de redes é considerada uma ferramenta útil para melhor compreender o processo de empreendedorismo internacional, uma vez que a participação em redes contribuiria para a identificação de oportunidades de negócios e de sua exploração bem-sucedida. A análise baseada na constituição de redes permitiria identificar laços externos econômicos e não econômicos - que as empresas mantêm. Contudo, Rossiter (2003) parece correta ao chamar a atenção para o fato de que a abordagem de redes tende a privilegiar a natureza das relaçóes organizacionais entre atores e a ignorar outros fatores, por exemplo, ambiente institucional, posição da empresa e seus recursos, assim como o papel do empreendedor individual.

Neste estudo descritivo e exploratório, julgou-se que a abordagem multidimensional - que considera uma combinação de fatores incluindo o contexto econômico-institucional, características dos agentes, além de diferentes níveis de análise (econômico e não econômico, estrutural e individual/subjetivo) - seria a mais adequada para compreender o fenômeno em questão, sobretudo no que se refere às economias emergentes (Rossiter, 2003).

Como já mencionado, os resultados da pesquisa evidenciam diferenças significativas quanto a características e desempenho das empresas investigadas, se comparadas às descritas pela literatura que se reporta a países de capitalismo maduro. Tais diferenças podem ser atribuídas à chamada dependência de trajetória (path dependence). Conforme 
North et al. (2007) advertem, não basta adotar ou copiar fórmulas organizacionais e institucionais externas, visto que escolhas atuais são, de alguma maneira, resultado de escolhas do passado e interferem na configuração do presente. No entanto, ao mesmo tempo que se observam persistências de escolhas do passado, há tendências que se contrapóem e desafiam os condicionantes históricos. Este é um embate em processo no país, no que se refere às tendências da chamada "nova economia", ${ }^{3}$ cujo futuro ainda não está definido.

Nosso objetivo é, sobretudo, o de apresentar alguns dados sobre a tentativa de modernos empreendedores de adequar-se a novas formas de organização econômica, transferindo para o país práticas de sucesso em outros contextos, mas pouco usuais no Brasil.

A próxima seção aborda a ação governamental que vêm sendo implementada no país desde final dos anos de 1990, com vistas a reduzir a defasagem que o separa do novo paradigma de desenvolvimento, e elenca as principais dificuldades que se apresentam à consecução desse objetivo.

\section{Brasil e as iniciativas de catching up}

Desde o final dos anos de 1990, os governos brasileiros vêm implementando políticas que favoreçam a transferência de conhecimento científico e/ ou tecnológico visando ao desenvolvimento de capacidade inovadora no país e à internacionalização das empresas, incluindo as MPMEs. São exemplos os Fundos Setoriais de Ciência e Tecnologia, instituídos em 1999, e o Projeto Inovar de 2000, criado para financiar pesquisadores para atuar em empresas. Em 2003, foi lançado o documento Diretrizes de Política Industrial, Tecnológica e de Comércio Exterior (PITCE), incentivando a integração do sistema produtivo com a inovação tecnológica e a competitividade no mercado exterior; em 2004, foi promulgada a Lei de Inovação - Lei no 10.973, formulada no governo anterior, visando estimular a participação de universidades e institutos de pesquisa públicos na produção de inovação (Morais, 2008; Viotti, 2008).

Em 2005, a chamada Lei do Bem instituiu incentivo fiscal às empresas que desenvolvem pes- quisa tecnológica com a contratação de pesquisadores. ${ }^{4}$ Outros programas e mecanismos de crédito e subvençôes têm sido criados, como a capitalização de fundos de investimento em empresas inovadoras. Em maio de 2008, foi instituída a Política de Desenvolvimento Produtivo, privilegiando áreas estratégicas, como Tecnologias da Informação e Comunicação (TICs), Nanotecnologia, Biotecnologia, Energia Nuclear, entre outras, com o objetivo de incentivar o aumento do investimento privado em $\mathrm{P} \& \mathrm{D}$, visando à maior participação do Brasil no comércio internacional.

A internacionalização de MPMEs constituiu uma das quatro metas da Política de Desenvolvimento Produtivo, do Ministério do Desenvolvimento, Indústria e Comércio Exterior (MDIC). Em 2011, foi criada a Empresa Brasileira de Pesquisa e Inovação Industrial (Embrapii), tendo como parceiro o Instituto Fraunhofer, da Alemanha, com o objetivo de "expandir o sistema de inovação e atender principalmente médias e pequenas empresas" (nas palavras do então Ministro de C\&T Aluísio Mercadante) $)^{5}$.

Apesar dos incentivos implementados desde final dos anos de 1990, os resultados quanto à capacidade do país para adequar-se ao novo paradigma, em termos gerais, não são muito animadores, conforme indicaçôes de diferentes levantamentos.

O Índice Global de Inovação 2017 (The Global Innovation Index - GII) avaliou, com base em um conjunto robusto de dados estatísticos, a capacidade de inovação de 127 países. ${ }^{6}$ Dentre estes, o Brasil foi classificado na posição $69^{a}$ do GII, sendo sua taxa de eficiência de inovação (média entre os resultados da inovação e os investimentos na área) de 0,52 , ocupando a posição 99a (Cornell, Insead e Wipo, 2017). Tais resultados são ratificados, de forma geral, pela Pesquisa de Inovação 2014 (Pintec) (IBGE, 2016).

As dificuldades enfrentadas pelo país decorrem de gargalos econômicos e institucionais. A seguir, são destacados alguns desses obstáculos para uma breve contextualização do ambiente de inovação no Brasil.

Dispêndios modestos em atividades de $\mathrm{P} \& \mathrm{D}$ fator de grande relevância para a produção de inovação -, se comparados ao crescimento significativo dos gastos em nível mundial, estimado como tendo sido duplicado no período entre 2003 e 
2013 (Science \& Engineering Indicators, 2016). No Brasil, o dispêndio em atividades de P\&D, no período entre 2000 e 2013, passou de 1,04 para 1,24 (Brasil, Ministério da Ciência, Tecnologia e Inovação, 2015).

Por outro lado, o setor privado nacional investe pouco em P\&D (em 2013, investiu 0,52\% do PIB, e o governo, $0,71 \%$ ) se comparado a países que se encontram na fronteira tecnológica, onde o setor privado é responsável pela maior parte dos investimentos na área: Coreia do Sul (78,5\%), Japão (76,1\%) e China (76,6\%); Estados Unidos (70,6\%) e Alemanha (68\%) (Science \& Engineering Indicators, 2016). Falta ao país a cultura da inovação, possivelmente resultado de um modelo de industrialização baseado em políticas protecionistas, que, ao invés de incentivar a competição, resulta em acomodação.

A pauta de exportaçóes reflete o baixo nível de inovação da produção brasileira: em 2014, as exportaçóes de produtos manufaturados era constituída em cerca de $40 \%$ por setores de baixo e médio baixo conteúdo tecnológico, a maioria com baixa ou nenhuma contribuição de $\mathrm{P} \& \mathrm{D}$, tornando-os produtos pouco competitivos no mercado mundial. O restante era constituído por $41 \%$ de produtos não industriais e apenas $20 \%$ de produtos de alto e alto médio conteúdo tecnológico (Gomes e Silva da Cruz, 2015).

O país carece de diplomados em cursos de ciências e engenharia, assim como de pesquisadores considerados agentes indutores da inovação. Havia em 2009, na força de trabalho no Brasil, 1,4 pesquisador por mil habitantes; na Coreia do Sul, eram 10,4 pesquisadores por mil habitantes (Brasil, 2009).

As práticas negociais no país são afetadas pela baixa racionalidade e pouca eficiência do sistema. O relatório anual, do Banco Mundial, Doing business 2016: medindo qualidade e eficiência, avaliou o grau de facilidade de realizar negócios em uma economia - em especial, em relaçáo aos pequenos e médios empreendimentos -, e classificou, em sua edição de 2016, o Brasil na 116a posição entre 189 países, atribuindo-lhe um score de 57,67 pontos, em uma escala de 0 a $100 .^{7}$

Os dados apresentados evidenciam algumas das dificuldades do ambiente econômico brasileiro e a dimensão dos desafios a serem enfrentados por empreendedores inovadores que pretendam se integrar à nova economia e se internacionalizar. Observe-se que o Brasil é o país menos integrado internacionalmente entre os componentes do BRIICS (Brasil, Rússia, Índia, Indonésia, China e África do Sul) (OCDE, 2014).

Ao apresentar, a seguir, alguns resultados da pesquisa realizada, deve-se considerar o contexto de atuação indicados anteriormente, em que se encontram os agentes investigados.

\section{A pesquisa}

Não há consenso sobre a definição de MPMEs, nem entre países e nem mesmo internamente aos países. Em razão das particularidades dos setores investigados, adotou-se, no estudo realizado, a definição de micro, pequenas e médias empresas considerando o número de empregados, ou seja, respectivamente até 9, até 49 e até 100 empregados, seguindo a divisão proposta, no Brasil, pelo Sebrae/IBGE para empresas de serviços, visto que, a rigor, as empresas investigadas, em sua maioria, poderiam ser classificadas como pertencendo ao setor de serviços ou como estando no limiar entre os setores de serviços e de manufatura.

Foram investigadas empresas atuando nos setores de ciências físicas e da vida, de tecnologias da informação e comunicação, e de consultoria, localizadas nas cidades do Rio de Janeiro, São Paulo, Campinas, Porto Alegre (região metropolitana) e Florianópolis. A seleção foi realizada a partir de consulta a sites (associaçóes de empresas, incubadoras e parques tecnológicos), indicação de pesquisadores, gerentes de parques tecnológicos e de incubadoras e também de entrevistados. Seleção essa que não seguiu o princípio de aleatoriedade, nem restringiu o setor de atuação, o que impóe limites aos resultados da pesquisa e às conclusóes apresentadas.

A coleta principal de dados ocorreu mediante a aplicação de 60 questionários respondidos em presença por um dos sócios com capacidade decisória na empresa. Os dados foram analisados com o auxílio do software SPSS. As respostas às questóes foram gravadas com o intuito de obter informaçóes adicionais, apresentadas em comentários, e explicações espontâneas dos entrevistados, que complementam o registro da resposta fechada. 
Das 60 empresas entrevistadas, 48 eram efetivamente internacionalizadas (de acordo com os critérios estabelecidos) e 12 não internacionalizadas. A seleção das empresas foi definida pela presença de atividade inovadora, tamanho e de experiências de internacionalização, no presente ou em passado recente, assim como pela manifestação de objetivo de internacionalização futura (busca de informação e/ ou oportunidades) ou, ainda, por já se encontrarem em processo/negociação nesse sentido.

As empresas investigadas foram divididas em três grupos: internacionalizadas born global (30), internacionalizadas (18) e não internacionalizadas ${ }^{9}$ (12). Realizou-se levantamento exploratório, comparando os três grupos de empresas na expectativa de encontrar diferenças que pudessem auxiliar na melhor compreensão do fenômeno em estudo. Porém, ao contrário do esperado, praticamente não se observaram diferenças significativas entre os grupos de empresas, o que pode ser resultado da natureza da amostra, que focou em empresas internacionalizadas (no presente, em passado recente ou em futuro próximo). Sendo assim, decidiu-se considerar o conjunto das 60 empresas, chamando a atenção para as particularidades de um e outro grupo, quando existentes.

As empresas investigadas, em sua maior parte, são de micro ou pequeno porte, atuando predominantemente no setor de "desenvolvimento de software" (19), mas também em "fabricação de bens tecnológicos" (13), "consultoria de gestão empresarial” (12), biotecnologia (4), cadeia do petróleo (5) e serviços de TICs (7).

Cabe mencionar que os setores com base em conhecimento apresentam características próprias, por exemplo, o setor de biotecnologia comparado a outros setores, como o de tecnologias da informação e comunicação, ${ }^{10}$ é mais dependente de conhecimento científico (ciência básica), exige maior volume de recursos e período mais longo de tempo (cerca de 10 a 15 anos) para comercializar um produto; além disso, obedece à regulação mais estrita. Esse setor apresenta riscos e incertezas mais elevados que outros e requer estratégias mais elaboradas para inovar e para consolidar-se internacionalmente. Portanto, a variedade de setores examinados na referida pesquisa limita generalizaçóes.
Inovação e internacionalização e as empresas investigadas

O processo de catching up torna-se uma necessidade em razão do novo paradigma de desenvolvimento; contudo, como já referido, o país apresenta limites à consecução desse objetivo, ainda que conte com incentivos públicos e interesse de pesquisadores-empreendedores. Diante de condiçôes particulares, procurou-se investigar de que forma os empreendedores pesquisados atingem os objetivos de inovar e internacionalizar-se. Que fatores favoreceram ou limitaram seus objetivos? De que modo exploraram oportunidades internacionais e quais estratégias desenvolveram para chegar à internacionalização? Considerando-se como dado o contexto estrutural, ou seja, novas tecnologias, facilidade de comunicação e globalização, buscou-se avaliar alguns fatores considerados relevantes pela literatura para o processo de internacionalização, como fatores de ordem pessoal (idade, capital social, pertencimento a redes de colaboração), político-social (políticas públicas; arcabouço institucional) e cultural (imagem do país).

Ao examinar-se a natureza do processo de internacionalização das empresas investigadas, chamam a atenção diferenças associadas ao período de fundaçâo das mesmas (empresas fundadas até o final da segunda metade dos anos de 1990 e as fundadas após esse período), em razão de particularidades dos contextos organizacionais e institucionais correspondentes, tanto em termos nacionais como internacionais.

O período de fundação da empresa indicou diferenças quanto à estratégia e forma de internacionalização. Para as empresas investigadas, surgidas nos anos de 1980 e 1990, a internacionalização não era uma possibilidade e ocorreu alguns anos após a sua criação, de forma gradual e baseada na proximidade (foco na América Latina), seguindo o chamado modelo Uppsala. Segundo o depoimento de um dos entrevistados, para atingir o mercado internacional teria antes que se consolidar no mercado interno; com a abertura do mercado e a competição das empresas estrangeiras, a pergunta era: "o que vou fazer lá fora se não consigo competir com as empresas estrangeiras no mercado doméstico?” 
Dentre as 14 empresas entrevistadas, criadas antes de 1999 (início dos incentivos públicos), somente 2 empresas foram consideradas born global, em comparação com 17 empresas, dentre as 44 empresas fundadas a partir de 1999. Constata-se que, após esse ano, a internacionalização entre os pequenos e médios empreendedores inovadores tornou-se uma possibilidade não apenas mais frequente, mas também mais imediata.

Nos anos de 1980 e na maior parte dos anos de 1990, o empreendedorismo inovador carecia de incentivos públicos ou privados e, nessas condiçóes, o fenômeno era condicionado, sobretudo, pelo fator subjetivo, como expressa o sócio de empresa criada em 1981:

[...] as oportunidades não estavam aparentes; fomos buscar a oportunidade; havia dúvida sobre o que fazer; fomos empurrados pelo desejo de empreender. [...] Me formei na UFRGS, em Engenharia Eletrônica [...] éramos 24 formandos, 20 tornaram-se funcionários públicos, hoje, aposentados com salário integral [refere-se a estes com desdém]; eu, queria ser empreendedor (quando adolescente, fabricava e vendia “gadgets”) - está no DNA da família.

A ausência de financiamento exigiu a mobilização de recursos próprios, que, segundo o entrevistado, limitou o crescimento mais rápido da empresa (hoje, conta com financiamentos do BNDES e Finep). Neste caso, o "espírito empreendedor", a forte motivação pessoal e o capital social sobrepuseram-se às condiçôes socioinstitucionais desfavoráveis.

No caso das empresas criadas a partir do final dos anos de 1990 e durante o século XXI, o contexto apresenta-se muito diferente, marcado pela globalização e pela revolução tecnológica, que contribuíram para produzir mudanças econômicas, sociais e culturais significativas. Internamente, a recuperação econômica e o início de incentivos públicos criam condiçóes para a emergência do novo paradigma no Brasil, em novas bases.

Se, no exemplo descrito na entrevista, destaca-se a importância do "espírito empreendedor" (fator subjetivo), no caso a seguir - pequena empresa inovadora, característica da nova economia - so- bressai a influência das novas condiçóes econômicas e institucionais do país. Essa empresa foi criada em 1999 por um jovem com doutorado na Universidade de Alberta, Canadá, onde obtivera experiência como cientista-empreendedor. Ao regressar ao Brasil, a alternativa profissional mais atraente era a carreira acadêmica, da qual gostava e que pretendia abraçar. Nessa ocasião, o governo do Estado do Rio Grande do Sul, onde residia, criou uma incubadora tecnológica, oportunidade que fez o jovem decidir colocar em prática sua experiência como cientista-empreendedor. Instalou-se em uma sala da incubadora "contando apenas com uma mesa e um computador" (depoimento do sócio-fundador). Retomou os contatos com os cientistas canadenses com quem trabalhara, iniciando uma profícua colaboração. A empresa tornou-se uma das mais promissoras pequenas empresas baseadas em conhecimento, na área de biotecnologia, no Brasil. Hoje, o empreendedor possui subsidiária no Canadá e trabalha em colaboração com cientistas canadenses e alemães na produção de vacina contra o câncer de próstata (já com depósito de patente nos Estados Unidos). O entrevistado explica:

[...] o valor da empresa está em sua capacidade de transformar conhecimento em valor, sem chão de fábrica; pode não ter produto, mas tem valor. O exemplo da vacina é a de um longo percurso, marcado por conhecimento, estudo clínico, patente depositada, possibilidade de ser aplicada em outros tumores etc. [...] daí o valor [...] a empresa é um enorme P\&D.

Com a obtenção da patente, o entrevistado estima que a avaliaçáo da empresa (valuation) possa passar de US\$ 30 milhóes para US\$ 120 milhóes. Mantém também intensa rede de colaboração formal (sob contratos) com universidades brasileiras e internacionais.

Condicionantes sociais, econômicos e institucionais parecem ter tido, nesse último período, papel relevante, inclusive para que aflorasse o "espírito empreendedor" em quem o empreendedorismo não era, inicialmente, uma "vocação". No entanto, como se verá adiante, o "espírito empreendedor", na maioria dos casos estudados, se combina, para- 
doxalmente, com uma internacionalização de baixa pró-atividade.

A seguir, analisam-se algumas variáveis identificadas pela literatura como tendentes a desenvolver orientação e visão internacional (Oviatt e McDougall, 1995). Entre elas, destacam-se: nível educacional dos empreendedores, por estar relacionado com a capacidade da empresa de absorver conhecimento e transformá-lo em inovação (Cohen e Levinthal, 1990; Zahra e George, 2002); experiências anteriores, profissionais ou não, de empreendedores no exterior (Weerawardena et al., 2007); participação dos empreendedores em redes de negócios, o que contribuiria para aumentar o intercâmbio de informações, favorecendo a identificação de oportunidades de negócios internacionais e elevando as possibilidades de sucesso.

Estudos pós-graduados são importantes para a prática da pesquisa - atividade requerida pelo empreendedorismo intensivo em conhecimento; as experiências no exterior constituem um valioso capital social, ao ampliar o acesso à informação sobre oportunidades internacionais através de conexôes e interaçóes sociais, anteriores às iniciativas econômicas, contribuindo para desenvolver orientação e visão internacional, com reflexos correspondentes no que se refere à internacionalização (Oviatt e McDougall, 1995; Cohen e Levinthal, 1990; Zahra e George, 2002; Weerawardena et al., 2007).

O nível de escolaridade dos empreendedores investigados mostrou-se elevado: apenas 2 respondentes declararam não possuir diploma de curso superior entre 55 respostas válidas. Considerando-se os dois sócios principais: a maioria informou ter realizado (ou estar realizando) estudos pós-graduados no país ou no exterior, em cursos de mestrado em negócios (MBA), 24; mestrado acadêmico, 24; e doutorado, 16. Os estudos pós-graduados são importantes porque criam uma relação de intimidade com a pesquisa - atividade fundamental para a produçáo de inovação, cuja presença nas empresas brasileiras é insignificante ${ }^{11}$ (esse tópico será abordado adiante).

A experiência no exterior constitui um valioso capital social, ao ampliar o acesso à informação sobre oportunidades internacionais através de conexóes e interações sociais, anteriores às iniciativas econômicas.
Em relação a experiências no exterior anteriores à criação do negócio (profissionais ou de estudos ou ambas), 36 respondentes indicaram ter tido experiências ou profissional ou de estudos ou ambas, no exterior, entre 51 respostas válidas. $\mathrm{O}$ número elevado de respostas afirmativas tenderia a representar maior acesso a informaçóes sobre negócios fora do país, que poderiam favorecer a internacionalização da empresa, inclusive a internacionalização precoce, algo a ser mais bem explorado em estudos futuros.

A participação em redes de colaboração é também considerado fator crucial como estímulo ao processo de empreendedorismo internacional. As referências mais frequentes de parcerias apontadas pela maioria dos respondentes à pesquisa foram com universidades e participação em feiras. A parceria com a universidade foi descrita, na maioria das vezes, não como envolvimento em projetos de pesquisa, mas como contratação de estagiários, o que não deixa de ser importante, visto que a troca de conhecimento tende a ocorrer, ainda que de forma menos eficiente. Nas demais opçóes - amizades, áreas de interesse, associaçóes, ambiente de trabalho, missóes -, a maior parte das respostas foi negativa.

Relativamente à relevância das redes de colaboração para o sucesso de negócios, cabe mencionar dois casos bem-sucedidos entre os investigados, associados a redes de amizade. Ambos se referem a empresas constituídas por pesquisadores que atuam na universidade. No primeiro, a empresa foi criada para atender à solicitaçáo de serviço de amigos/ ex-colegas, funcionários de uma grande empresa estatal. Em continuidade, a empresa se consolidou na prestação desse serviço, tornando-se fornecedora dele a outras grandes empresas internacionais de petróleo. No segundo caso, a empresa de biotecnologia foi criada por sugestáo de um amigo envolvido com a política de CT\&I, no país, que viu, nos pesquisadores em questão, perfis adequados de cientistas-empreendedores para cumprir objetivos de política de incentivo à inovação que estava sendo implementada.

Como se pode constatar, fatores considerados favorecedores de internacionalização encontram-se bem representados na pesquisa realizada, em especial, no que se refere ao número elevado de sócios pós-graduados e com experiências prévias de traba- 
lho e/ou estudos no exterior. Contudo, a participação em redes apresenta resultado menos significativo.

Os fatores antes referidos constituem uma mudança de ambiente, que tende a ampliar oportunidades a pessoas com perfil mais próximo de pesquisador do que de "empreendedor". A grande maioria dos micro, pequenos e médios empreendedores inovadores, no Brasil, dos anos 2000, não têm influência familiar na escolha de sua ocupação atual; as influências marcantes decorreram, principalmente, de experiências em pesquisa, no país e/ou no exterior (em estudos, trabalho ou em ambas atividades); de condiçôes criadas por incentivos públicos; por pertencimento a redes de colaboração diversas; pela presença das novas tecnologias; pelo ethos da época.

A idade dos sócios e o fenômeno da internacionalização parecem, também, estar relacionados: em nossa amostra, a maioria dos sócios estava na faixa de 30 a 39 anos. Esse grupo experimentou os efeitos da estabilização econômica do país, da globalização e da revolução tecnológica recente, ainda jovem, o que pode ter contribuído para influenciar a escolha profissional. A geração mais velha também viveu o efeito desses processos, mas o experimentou em condiçôes diferentes, após a formação educacional e a definição profissional.

A relevância do "fator geracional" se reforça quando se constata que, dentre as 48 empresas internacionalizadas investigadas, 19 foram consideradas precocemente internacionalizadas, as chamadas born global. As empresas investigadas acompanharam a novidade da internacionalização das MPMEs, na atualidade, demonstrando que o processo não é necessariamente evolutivo e gradual. $\mathrm{O}$ fenômeno das MPMEs born global, definido como "uma organização empresarial que, desde o início, procura obter vantagem competitiva significativa a partir da utilização dos recursos e de operaçóes em vários países" (McDougall, Shane, e Oviatt, 1994, p. 470; Oviatt e McDougall, 1994, p. 49); ${ }^{12}$ é, em geral, característico de empresas de pequeno porte, de base tecnológica, que atuam no mercado internacional desde que foram criadas.

Um aspecto que chama a atençấ foi a baixa pró-atividade dos empreendedores investigados em relação à internacionalizaçáo. A maioria das empresas internacionalizadas (28 das 48) internacionalizou-se de forma reativa, ou seja, responderam a demandas de clientes. Mesmo entre as 30 empresas born global, 19 delas foram consideradas como de internacionalizaçáo reativa e apenas 11 como de internacionalizaçáo pró-ativa. $\mathrm{O}$ fator globalização (facilidades de acesso à informação e à comunicação internacional) parece ter sido mais significativo para a internacionalização das empresas investigadas do que a iniciativa dos empreendedores. Depoimentos dos respondentes tendem a confirmar essa hipótese:

A internacionalização surgiu em 2012 por conta da divulgação de produtos feita através de artigos acadêmicos [...]

A internacionalização foi sob demanda, o mercado internacional nos escolheu.

Eles acessaram o nosso site, não fui eu quem fui atrás deles, eles que solicitaram o material.

Por demanda, a partir de artigo acadêmico de um dos sócios, encontrado na internet.

A constatação sobre "baixa pró-atividade" anteriormente referida deve ser contextualizada, considerando que, desde meados dos anos de 1990, as oportunidades no mercado doméstico estiveram em expansão e tornavam a internacionalização uma alternativa pouco atraente em face das dificuldades de ordem regulatória e burocrática impostas às empresas brasileiras com possibilidades de internacionalização. Obstáculos regulatórios estão na contramão das oportunidades geradas pelo alcance da visibilidade e comunicação internacional. Apenas o site da empresa em língua inglesa (conforme depoimento de entrevistado) pode ser suficiente para gerar negócios:

Identifiquei espaço, oportunidade, lancei no ambiente digital e então entraram em contato.

Apesar das dificuldades, há os que (em menor número) estão dispostos a internacionalizar-se.

Qualquer produto que fazemos já está pronto pra a internacionalização, só precisa de documentação. Tudo já é feito em inglês e depois traduzido pra o português. Desde o início, a empresa se preocupa com o mercado externo - desde o desenvolvimento 
do site em inglês (língua de programador, tanto brasileiros como estrangeiros).

Constatou-se, contudo, que mesmo as empresas investigadas que se internacionalizaram o fizeram, em sua maioria, em pequena escala, o que demonstra a baixa contribuição do valor gerado pela internacionalização ao faturamento delas: dos 41 respondentes, 25 declararam que a contribuição da internacionalização era de até $10 \%$, e 18 destas declararam ser de 5\%; 9 empresas declararam ser de $11 \%$ a $40 \%$; e 7 empresas, mais de $40 \%$. Ou seja, a internacionalização teve baixo impacto econômico para a maioria delas, o que tende a indicar baixo nível de inovação e de competitividade das empresas investigadas.

Apesar do baixo desempenho, a quase totalidade dos respondentes avaliou positivamente os benefícios da internacionalização, concordando com as afirmaçóes apresentadas: "aumenta valor da marca pela presença no exterior"; "melhora a imagem no mercado nacional"; "aumenta a competitividade em face de concorrentes domésticos"; "potencializa a capacidade de inovação tecnológica"; "favorece o desenvolvimento de novos produtos e segmentos", entre outras indicaçóes positivas. Conclui-se que uma percepção positiva a respeito da internacionalização não é capaz sozinha de estimular açóes pró-ativas. Essa é uma questão a ser mais bem investigada; no entanto, hipóteses avaliando o papel de variáveis como "baixo nível da inovação", "dificuldades regulatórias e burocráticas", "isolamento econômico do país", poderiam ser consideradas.

Perguntados sobre os obstáculos à internacionalização, os respondentes indicaram vários problemas: a maioria apontou dificuldades como burocracia, custos altos (taxas) para internacionalizar e falta de pessoal qualificado. Alguns depoimentos são ilustrativos:

Pessoal é grande problema: hoje, na empresa há um pesquisador irlandês e um cubano [...] estamos buscando empregados na Europa, embora o processo de permissão de trabalho seja bastante complicado.

[...] se você vence no Brasil, você vence em qualquer lugar, pois aqui é muito difícil: con- tratação é difícil, reter talentos é difícil, a burocracia é difícil.

[...] diferença brutal entre China e Brasil; a China construiu um parque monumental de eletrônica, enquanto o Brasil se perguntava o que devia fazer. Essa defasagem mostra o atraso do Brasil, a falta de conhecimento do que estava ocorrendo no mundo, em última análise, a falta de internacionalização.

Dados de pesquisa apresentados no relatório Doing business 2017: igualdade de oportunidades para todos corroboram essa avaliação. ${ }^{13}$ Entre 190 economias, o Brasil encontra-se na: $123^{a}$ posição na classificação geral (inclui 41 indicadores); $175^{\mathrm{a}} \mathrm{em}$ "facilidade para abrir uma empresa"; $181^{a}$ quanto a "pagamento de impostos"; e 149a em relação a "comércio internacional", entre outras categorias. Apenas como ilustração, cabe referir que, para abrir uma empresa no Brasil, em média, são necessários 11 procedimentos (em países da OCDE, a média é de 4,8 procedimentos) e a demora é de 101,5 dias (em países da OCDE, a média é de 8,3 dias). Para pagamento de tributos, no Brasil, as empresas gastam em média 2.038 horas/ano (em países da América Latina, a média é de 342,6 horas/ano; em países da OCDE, é de 163,4 horas/ano). Na dimensão "comércio internacional”, no Brasil, para obter os procedimentos aduaneiros e documentação para exportar, as empresas despendem 49 horas (em países da OCDE, a média é de 12 horas) e o custo total é US\$ 959 (em países da OCDE, a média é de US\$ 150); para importar, a demora é de 63 horas (em países da OCDE, a média é de 9 horas) e o custo US\$950 (em países da OCDE, a média é de US\$115). ${ }^{14}$

Cabe destacar ainda, que o Brasil, segundo dados do Banco Mundial, é um dos países mais fechados comercialmente no mundo, com baixa participação de importações e exportaçóes em relaçâo ao PIB, o que não poderia ser explicado somente pelo tamanho do mercado doméstico, mas também por um modelo econômico voltado para a integração de cadeias de valor locais e não para a participação em redes globais de produção (Canuto; Fleischhaker e Schellekens, 2015). É importante frisar esses dados porque pesquisas têm mostrado não só os efeitos do ambiente institucional sobre a quantidade de 
pessoas envolvidas em atividades empreendedoras de todo tipo, como também o fato de que as instituiçóes importam na qualidade (inovador, internacional, etc.) do empreendedorismo entre os países, assim como em seu impacto no desenvolvimento econômico e social (Troilo, 2011; Boettke e Coye, 2009; Salman, 2014).

Em suma, em se tratando de condiçóes institucionais gerais para a atividade empreendedora, o Brasil ainda apresenta sérios obstáculos que reduzem a eficiência e o retorno dos incentivos públicos ao empreendedorismo intensivo em conhecimento e à internacionalização, ou seja, o ambiente institucional para internacionalização é marcado pelo contraste entre os objetivos de políticas e incentivos públicos para a inovação e internacionalização das MPMEs e as dificuldades de ordem regulatória, burocrática e institucional, como evidenciam os dados ora apresentados.

Ao lado dos problemas apontados, há que considerar que o país carece de uma cultura voltada à internacionalizaçáo econômica, decorrente de uma política protecionista que perdurou mais do que deveria. Nesse sentido, vale destacar a conclusão apresentada pelo estudo de Nogueira e Ferreira (2017), que, amparado em vasta literatura internacional sobre o tema e, principalmente, em robusto conjunto de dados estatísticos envolvendo 95 países de diferentes níveis de renda, afirma

[...] independentemente do nível de desenvolvimento financeiro, os países se beneficiam da abertura comercial, uma vez que o comércio facilita o acesso a bens de capital e insumos estrangeiros (em geral, mais baratos), implicando redução do custo do capital e estímulo ao investimento [...] o estímulo à abertura comercial e a oferta de incentivos à atração de investimento direto estrangeiro é positivo e estatisticamente significante nos regimes de baixa e alta renda ao ampliar o tamanho do mercado para os produtores e ao possibilitar os spillovers de conhecimento (Nogueira e Ferreira, 2017, pp. 549 e 541).

Outro paradoxo se verifica ao constatar-se que o fraco impacto da internacionalização sobre as empresas investigadas não corresponde à percepção dos respondentes sobre a relevância da internacio- nalização, visto que a quase totalidade dos entrevistados reconhece seus benefícios, em especial no que se refere à contribuição da internacionalização para elevar o nível da inovação. De um lado, a busca por inovação seria um proxy da propensão do empreendedor a correr riscos que, por sua vez, também está presente na decisão de internacionalizar a empresa. De outro lado, o grau de inovaçáo contidos nos produtos e serviços é fator estratégico de competitividade num contexto de economia globalizada; teoricamente, empresas inovadoras tenderiam a apresentar capacidades e condiçôes mais favoráveis que as demais para a sua inserção em mercados além-fronteiras nacionais.

Seria necessário avaliar com maior precisão o grau ou nível de inovação das empresas investigadas, isto é, a complexidade dos bens e serviços produzidos: baixo, baixo médio, médio, médio alto, alto. Porém, mensurar grau ou nível de inovação é tarefa difícil, em razão, especialmente, da ausência de consenso sobre indicadores a ser utilizados para estabelecer uma escala consistente.

Registro de patentes, por exemplo, é considerado um indicador pouco preciso, já que muitas patentes náo chegam a se tornar produtos comercializados ou inovaçôes, e muitas inovaçóes não são patenteadas (caso de software: transformações tecnológicas são mais rápidas do que concessão de patente). Apesar das restriçóes quanto à utilização de patentes como indicador de capacidade de inovação e desenvolvimento tecnológico, constata-se uma correlação positiva entre países com elevados níveis de desenvolvimento econômico-tecnológico, investimentos em P\&D e a posição destacada quanto ao pedido de patentes. ${ }^{15}$

$A$ atividade de $P \& D$ na empresa é indicador relevante de inovação, visto que está intimamente relacionada com a criação de capacidades internas e absorção de conhecimento para a criação de produto inovador.

No Brasil, em especial, o financiamento público pode ser considerado indicador de desempenho inovador da empresa, visto que a concessáo de financiamento resulta de aprovaçáo por especialistas da área a projetos que se propóem ao desenvolvimento de inovação, embora a ausência desse tipo de financiamento não caracterize, necessariamente, a ausência de inovação. 
$\mathrm{Na}$ tentativa de avaliar, ainda que de maneira aproximada e pouco precisa, o nível de inovaçáo de bens e serviços produzidos pelas empresas investigadas, foram utilizados os seguintes indicadores: registro de patentes, atividade de $\mathrm{P} \& \mathrm{D}$, financiamento público e interação com centros de produção de conhecimento.

Quanto ao registro de patentes, a maioria dos entrevistados (33) respondeu negativamente e 22 responderam positivamente. $\mathrm{O}$ número elevado de empresas sem patentes pode estar relacionado com o fato de que 38 empresas da amostra encontravam-se ou nos setores de "desenvolvimento de software" (19) e de "serviços relacionados a TICs" (7) ou em "serviços de 'consultoria" (12) - áreas que, em geral, não requerem registro de patentes. De qualquer forma, o número geral de empresas que respondeu não possuir patentes está em consonância com a posição do Brasil ${ }^{16}$ em relação aos dados internacionais, antes referidos, ou seja, apesar do crescimento mundial expressivo de pedidos de patentes, o Brasil mantém-se em posição bem abaixo à de seus pares no BRIICS.

Em relaçáo ao desenvolvimento de atividades de P\&D, constatou-se elevado número de respostas positivas: das 59 respostas válidas, 45 afirmaram desenvolver $\mathrm{P} \& \mathrm{D}$ interno e de forma permanente. Os respondentes descrevem a atividade de P\&D como um valor e como prática cotidiana da empresa:

[...] a empresa é um enorme P\&D.

[...] não tem como não estar em permanente pesquisa.

Fazemos juntos [com Alemanha] o desenvolvimento dos projetos, são os times daqui e de lá. Existe bastante troca entre os membros dos dois times.

A gente faz pesquisa diariamente.

$\mathrm{P} \& \mathrm{D}$ é a nossa essência.

Esse dado sobre P\&D sugere o início de uma possível mudança no meio empresarial brasileiro quanto à compreensão de que vantagem competitiva requer ir além da simples imitação. A atividade de P\&D é pouco praticada nas empresas brasileiras inovadoras: a Pesquisa de Inovação 2014 (Pintec), ${ }^{17}$ divulgada pelo IBGE (2016), investigou 132.529 empresas inovadoras (públicas e privadas) e registrou apenas 5\% de empresas com atividades de $\mathrm{P} \& \mathrm{D}$ interno; o modelo de inovação das empresas investigadas pela Pintec baseava-se, principalmente, na compra de máquinas e equipamentos.

Quanto a financiamento público (ou privado), das 59 respostas válidas, 34 responderam positivamente (excluídos financiamentos pessoais ou de familiares). Esse dado é também significativo, visto que a obtenção de recursos públicos ou privados requer a aprovação por especialista da área do projeto inovador.

Os bens e serviços produzidos pelas empresas investigadas estão, em sua maioria, nas áreas de: (1) desenvolvimento de software (como aplicativos, jogos, para utilização em celulares, tablets e outros meios eletrônicos; programas voltados a gerenciamento e controle de impressão, aumento de desempenho de processos industriais, maior eficiência de departamentos de Recursos Humanos, monitoramento de empregados, demanda/customização de empresas, desenvolvimento de plataformas); (2) fabricação de bens (como produtos de desinfecção para frigoríficos; equipamentos de monitoramento da fermentação alcoólica); e (3) consultoria de gestão empresarial (como automação de processos, reestruturação empresarial).

As empresas produtoras dos bens e serviços descritos podem ser classificadas como inovadoras com baixo ou baixo médio grau de complexidade, visto que seus produtos são rearranjos de produtos já existentes (inovação incremental). Sobre o desenvolvimento de softwares (produto da maioria das empresas investigadas), um dos respondentes resume com propriedade o que ocorre:

Brasil não tem uma cultura forte de software; o governo tem feito esforços, mas se comparado com a Índia, está bem atrás. Está melhor do que foi, mas não tem credibilidade no exterior, não tem uma boa imagem.

Essa percepção parece retratar a realidade com certa fidelidade; entretanto, outra resposta poderia complementá-la:

[...] estou trabalhando em uma coisa que já existe, mas estou trabalhando em novas con- 
cepçóes, novos processos [...] Nosso foco não é no produto é na solução.

Conclui-se que, embora atuando no nível de baixa inovação, essas empresas podem representar progressos que venham a evoluir para formas mais complexas de produção. O seu nível de inovação tende a se refletir no processo internacionalizaçáo, como se verá adiante.

Das empresas investigadas, poucas - cerca de dez empresas - produzem inovaçóes com maior grau de complexidade, aproximando-se de inovação de nível médio ou de médio alto. Alguns desses produtos são da área de: (1) biotecnologia, como biofármacos (produção de anticorpos com alto valor agregado), vacina anticâncer (depósito de patente nos Estados Unidos), enzima e derivados; (2) tecnologias da informação e comunicação (TICs), produtos eletroeletrônicos como controladores e medidores eletrônicos; e (3) cadeia de petróleo (inteligência de negócios com uso de geotecnologias, bens tecnológicos focado na manutenção de navios, softwares para análise de rochas).

Os dados apresentados revelam a diversidade e a complexidade para analisar o processo de internacionalização de empresas inovadoras no país. Seria equivocado buscar uma generalização no sentido de atribuir a um único fator o papel de ser o principal promotor ou limitador ao avanço da internacionalização das MPMEs nacionais. Fatores culturais interagem com variáveis subjetivas, institucionais, econômicas e sociais. Assim, o que se pode concluir pelas constataçóes observadas é que o nível de pró-atividade perante a internacionalização é bastante modesto em comparação a experiências internacionais.

\section{Consideraçôes finais}

A realização deste estudo resultou da preocupação com os desafios enfrentados pelo país em face do novo paradigma de desenvolvimento, baseado no conhecimento, inovação e internacionalização fatores de que o Brasil é reconhecidamente deficitário. Amplas oportunidades apresentam-se aos países emergentes, em especial a possibilidade de exploração de novos nichos de mercado em áreas como software, ciências biomédicas, fármacos, ener- gias renováveis, biotecnologia, nanotecnologias, biodiversidade, engenharia genética e economia verde. No Brasil, ainda que modesta, houve certa disponibilidade de recursos públicos destinados ao incentivo da inovação e internacionalização. Em que medida o país está se beneficiando dessas oportunidades para alcançar os objetivos esperados?

Sabe-se que condiçôes institucionais e culturais domésticas são pouco favoráveis ao país para a obtenção de resultados positivos, ao menos, no curto prazo. Ainda assim, conforme mostra o estudo realizado, observa-se um movimento de MPMEs intensivas em conhecimento em direção ao novo paradigma. De que maneira, porém, ocorre a internacionalização das MPMEs no Brasil? A análise dos dados de nossa pesquisa, ainda que de caráter exploratório, sugere algumas observações.

No caso brasileiro, o ambiente econômico, social e cultural parece tanto promover o processo de internacionalização - a globalização, a difusão das novas tecnologias e a indução por meio de políticas públicas - quanto enfraquecê-lo em termos gerais: ambiente fiscal desfavorável, burocracia excessiva, isolamento econômico-tecnológico do país, nível geral de educação e de qualificação dos recursos humanos insatisfatório, instabilidade econômica.

Elevados níveis de escolaridade e de experiências dos empreendedores no exterior, fatores considerados facilitadores para a internacionalização, em estudos realizados em países de alta renda, presentes entre os empreendedores investigados, não apresentaram, porém, o mesmo resultado no desempenho inovador das empresas investigadas na pesquisa. O que isso significa? Que alta escolaridade e experiência no exterior não teriam o mesmo peso para explicar a internacionalização no caso do Brasil? Sim e não.

Os resultados de nossa pesquisa sugerem a necessidade de melhor qualificar as hipóteses formuladas. A incapacidade da alta escolaridade para elevar o nível de pró-atividade na internacionalização parece indicar que, ao contrário do que ocorre nas universidades de países tecnologicamente avançados, a formação adquirida na universidade brasileira acha-se ainda presa ao modelo de universidade tradicional, que prioriza a formação voltada para a chamada pesquisa básica, em detrimento da "terceira missão", que 
preconiza transferência de conhecimento científico para a empresa, lócus do empreendedorismo intensivo em conhecimento. Essa característica da universidade brasileira pode explicar a fraca relação entre alta escolaridade de sócios de empresas inovadoras, em geral, e baixo nível de pró-atividade de internacionalização. Essa também pode ser a razão para justificar o emprego em tempo integral da maior parte dos pesquisadores brasileiros em universidades e náo em empresas, como ocorre nos países tecnologicamente consolidados. Conclui-se que ao relacionar alta escolaridade e internacionalização, é necessário não apenas indicar o nível de escolaridade, mas qualificar o tipo de formação oferecida.

$\mathrm{O}$ alto percentual de respostas indicando experiências dos sócios no exterior, no caso investigado, da mesma forma, não se traduz em impacto significativo das redes de negócios sobre a internacionalização de tais empresas. Talvez, mais decisivo do que experiências no exterior (acadêmicas e/ou profissionais) seja o tipo de padrão cultural próprio da realidade brasileira em relação ao mundo dos negócios, marcado pelo isolamento, imitação e, mais recentemente, inovação incremental, o que também contribuiria para a atitude reativa diante da internacionalização.

O suporte de políticas públicas - uma característica, no Brasil, desde o início do processo de industrialização - tende a criar uma forte expectativa sobre o Estado como fonte de incentivos e recursos, o que pode gerar um círculo vicioso: o processo é desencadeado por políticas públicas do setor de ciência e tecnologia e não pela iniciativa privada. Os padróes de acesso a fontes de financiamento entre as empresas pesquisadas ocorreu, majoritariamente, via "fontes pessoais, familiares e/ou do capital da própria empresa" (51 empresas); segue-se o financiamento público federal, estadual e/ou municipal e governos estrangei$\operatorname{ros}^{18}$ - (26 empresas), acessado pelo dobro do número de empresas com financiamento do setor privado (13 empresas), o que aponta para a tradicional tendência de busca pelo apoio do Estado - mesmo porque as fontes privadas de financiamento (capital de risco, capital anjo) são pouco atuantes no país.

Desse modo, constata-se, na maioria dos casos investigados, que, apesar de alta escolaridade, de experiências no exterior e de assumirem como inovadora a atividade do empreendimento, os empreendedores inserem-se na nova economia de forma "tradicional", algo como uma adaptação do velho para absorver o novo. São "novos" agentes atuando em um ambiente em que se mantêm normas e valores herdados de um tipo de industrialização que se opóe às exigências de inovação e de internacionalização. Acrescente-se a distância do tipo de formação acadêmica que, devotada à pesquisa, tende a ignorar a sociedade à sua volta.

Paralelamente, a esses aspectos "tradicionais" não se pode ignorar, conforme já mencionado, fatores institucionais que dificultam a internacionalização, bem como fatores socioeconômicos, como a falta de pessoal qualificado e o tamanho do mercado brasileiro.

Contudo, há um pequeno grupo de empreendedores entrevistados que nitidamente se destacam pela orientação em sintonia com a "nova economia”. Expostos às mesmas vicissitudes institucionais, eles foram capazes de superá-las, ao menos em parte. Uma investigação dirigida mais diretamente a esses casos torna-se necessária para que se possa compreender melhor como é possível superar barreiras aparentemente intransponíveis.

\section{Notas}

1 Rialp et al. (2005) selecionaram 38 artigos que consideraram mais relevantes, publicados em periódicos científicos no período 1993-2003. Levantamento semelhante foi feito por Gomes, Silveira e Amal (2010) em quatro periódicos internacionais de alto impacto, publicados entre 2000 e 2008, nos quais encontraram 26 artigos com foco no tema.

2 Para uma boa revisão do conceito, ver Aldrich (2005). Para os fins deste artigo, "empreendedorismo internacional" é "a descoberta, o agir, a avaliação e a exploração de oportunidades - através de fronteiras nacionais para a oferta futura de bens e serviços" (McDougall e Oviatt, 2003, p. 6).

3 Setores intensivos em conhecimento e tecnologia - (a) serviços: comércio, finanças e informação, educação e saúde; (b) manufatureiro: aeronáutico e espacial, comunicaçóes e semicondutores, computadores, fármacos e instrumentos de teste, medição e controle representavam $29 \%$ do produto interno bruto (PIB) mundial, em 2014; 40\% do PIB dos Estados Unidos 
e 30\% do PIB de países da OCDE e Japáo (Science \& Engineering Indicators, 2016). Porém, esse percentual é bem mais significativo, considerando-se que as novas tecnologias perpassam diferentes cadeias produtivas em todos os setores da economia Por exemplo, no setor automotivo, estima-se que $90 \%$ das inovaçóes atuais resultem da incorporaçáo de novas tecnologias.

4 Trata-se da Lei $\mathrm{n}^{\circ} 11.196$, de 21 de novembro de 2005 (Brasil, 2005).

5 Noticiado pela Anpei (Associaçáo Nacional de Pesquisa e Desenvolvimento das Empresas Inovadoras). Disponível em: <http://anpei.org.br/anpeinews/cni-e-governo-criam-empresa-para-inovacao-2/>. Acesso em: 12 out. 2017.

6 A edição de 2017 examinou 127 países/economias que representam $95,1 \%$ da população mundial e 98,6\% do PIB mundial (em dólares correntes dos Estados Unidos); ver Cornell, Insead e Wipo (2017).

7 Variáveis consideradas: "iniciar negócio", "liberação para construção", "registro de propriedade", "obtenção de eletricidade", "acesso a crédito", "proteção a investidores", "pagamento de taxas", "negócios além-fronteiras", "garantia de contratos" e "solução de insolvências" (Disponível em: <http://portugues.doingbusiness.org/ methodology>; acesso em: 23 out. 2017).

8 Não há consenso na literatura internacional sobre a "idade" da empresa para definir "internacionalizaçáo precoce" (born global). Estudiosos têm definido períodos de 3, 5, 10 e até 15 anos após data de criação da empresa. Neste estudo, foi definido como internacionalização precoce aquela ocorrida até 5 anos após a criação da empresa (Dib, Rocha e Silva, 2010).

9 Embora não internacionalizadas, um número significativo desse grupo de 12 empresas estava, no momento da pesquisa, buscando internacionalizar-se.

10 "A informática é de mais amplo acesso que a biotecnologia, realiza-se com equipamentos mais baratos e de mais fácil aquisição por parte dos indivíduos e grupos que a desenvolvem, e requer menor grau de especialização, ao menos no nível formal, que o exigido para um cientista ou tecnólogo em biotecnologia" (Trigueiro, 2006, p. 54).

11 A chamada Lei do Bem (Lei no 11.196/2005, Art. 21), visando incentivar a inovaçáo, prevê a subvenção de remuneração de pesquisadores, titulados como mestres ou doutores, empregados em atividades de inovação tecnológica em empresas (Brasil, 2005).

12 Para uma extensa bibliografia sobre o fenômeno, ver Meckl e Schramm (2005).

13 O Doing business mediu o ambiente regulatório quanto à facilidade para a atividade empresarial e empreendedora quanto a: abertura de empresa; obtenção de alvarás de construçấo; obtenção de eletricidade; registro de propriedades; obtenção de crédito; proteção dos investidores minoritários; pagamento de impostos; comércio internacional; execução de contratos e resolução de insolvência (Banco Mundial, 2017).

14 Os dados extraídos do Doing business 2017 referem-se à cidade de São Paulo.

15 Mais informações em: World Intellectual Property Organization (Wipo). Disponível em: <http://www.wipo. int/portal/en/index.html>. Acesso em: 15 fev. 2016.

16 Em 2013, a China liderava o crescimento do número de patentes (32,1\% do total mundial) e o Brasil ocupava a $24^{\text {a }}$ posição ( $1,5 \%$ do total mundial).

17 A Pintec abrange todas as empresas inovadoras com dez ou mais empregados.

18 O governo federal é o mais acessado, com 25 das 26 empresas. Cabe destacar que uma fonte de financiamento náo exclui outras, isto é, podemos ter numa empresa financiamento de governo federal e estadual, assim como de familiares ou do setor privado.

\section{BIBLIOGRAFIA}

ALDRICH, H. E. (2005), "Entrepreneurship", in N. Smelser, Neil e R. Swedberg, The Handbook of Economic Sociology, 2. ed., Princeton, Princeton University Press.

BANCO MUNDIAL. (2016), “Doing business: medindo qualidade e eficiência. Classificação das economias". Disponível em: <http://portugues.doingbusiness.org/rankings $>$. Acesso em: 21 out. 2017.

BANCO MUNDIAL. (2017), "Doing business: igualdade de oportunidades para todos. Metodologia”. 2017. Disponível em: <http://portugues.doingbusiness.org/methodology>. Acesso em: 21 out. 2017.

BOETTKE, Peter J. \& COYNE, Christopher J. (2009), "Context matter: institutions and entrepreneurship". Foundations and Trends in Entrepreneurship, 5 (3): 135-209.

BRASIL. Ministério da Ciência, Tecnologia e Inovação. (2015), "Indicadores Selecionados de Ciência, Tecnologia e Inovação”. Disponível em: <http://oic.nap.usp.br/wp-content/ 
uploads/2015/08/237254.pdf>. Acesso em: 18 out. 2017.

BRASIL. Ministério da Ciência, Tecnologia, Inovaçóes e Comunicaçóes. (2009), "Indicadores Nacionais de Ciência, Tecnologia e Inovação”. Disponível em: <http://www.mctic.gov.br/mctic/opencms/indicadores/comparacoesInternaconais/8.2.2.html>. Acesso em: 23 out. 2017.

BRASIL. Presidência da República. Casa Civil. Lei no 10.973 , de 2 de dezembro de 2004. Dispóe sobre incentivos à inovação e à pesquisa científica e tecnológica no ambiente produtivo e dá outras providências. Disponível em: <http://www.planalto.gov.br/ccivil_03/_ato2004-2006/2004/lei/ 110.973.htm >. Acesso em: 24 out. 2017.

BRASIL. Presidência da República. Casa Civil. Lei no 11.196, de 21 de novembro de 2005. Institui o Regime Especial de Tributação para a Plataforma de Exportação de Serviços de Tecnologia da Informação - REPES, o Regime Especial de Aquisição de Bens de Capital para Empresas Exportadoras - RECAP e o Programa de Inclusão Digital; dispóe sobre incentivos fiscais para a inovação tecnológica; altera [diversos dispositivos]; e dá outras providências. Disponível em: <http://www. planalto.gov.br/ccivil_03/_ato2004-2006/2005/ lei/l11196.htm>. Acesso em: 20 out. 2017.

CANUTO, Otaviano; FLEISCHHAKER, Cornelius \& SCHELLEKENS, Philip. (2015), The curious case of Brazil's closedness to trade. World Bank (Policy Research Working Paper). Disponível em: <http://documents.worldbank. org/curated/en/345971468186871924/pdf/ WPS7228.pdf>. Acesso em: 11 out. 2017.

COHEN, Wesley \& LEVINTHAL, Daniel. (1990), "Absorptive capacity: a new perspective on learning and innovation". Administrative Science Quarterly, 35 (1): 128-152. (Special issue: Technology, Organizations, and Innovation).

CORNELL University, Insead, and WIPO: The Global Innovation Index 2017: innovation feeding the world, Ithaca, Fontainebleau, and Geneva. Disponível em: <www.globalinnovationindex.org>.

DE NEGRI, F. et al. (2016), "Inovação no Brasil: crescimento marginal no período recente". Ipea. (Nota Técnica, n. 34). Disponível em: $<$ www.ipea.gov.br>.
DIB, Luis; ROCHA, Angela \& SILVA, Jorge Ferreira. (2010), "The internationalization process of Brazilian software firms and the born global phenomenon: examining firm, network, and entrepreneur variables". Journal of International Entrepreneurship, 8 (3): 233-253.

FERRARY, Michel \& GRANOVETTER, Mark. (2009), "The role of venture capital firms in Silicon Valley's complex innovation network". Economy and Society, 38 (2): 326-359.

GOMES, Gerson \& SILVA DA CRUZ, Carlos Antônio. (2015), Vinte anos da economia brasileira - 1995-2014. Brasília, Centro de Altos Estudos Brasil Século XXI. Disponível em: <http:// plataformapoliticasocial.com.br/wp-content/ uploads/2015/04/VINTE-ANOS-DA-ECONOMIA-BRASILEIRA-1995-2014.pdf>. Acesso em: 20 jan. 2016.

GOMES, Giancarlo; SILVEIRA, Amélia \& AMAL, Mohamed. (2010), "Internacionalização de pequenas e médias empresas em periódicos de administração com alto fator de impacto: 2000-2008". Iberoamerican Journal of Strategic Management, 9 (3): 112-138. Disponível em: <http://www.revistaiberoamericana. org/ojs/index.php/ibero/article/view/1692>. Acesso em: 12 out. 2017.

GRANOVETTER, Mark. (2000), "The economic sociology of firms and entrepreneurs", in R. Swedberg (ed.), Entrepreneurship: the social science view, Oxford, Management Readers.

HERRMANN, Andrea. (2010), "Against the Schumpeterian mainstream: review of institutional approaches to entrepreneurship". Socio-Economic Review, 8 (4): 735-746.

IBGE. Pesquisa de Inovação 2014. (2016), Rio de Janeiro, IBGE. Disponível em: <https://ww2. ibge.gov.br/home/estatistica/economia/industria/pintec/2014/default.shtm>. Acesso em: 16 out. 2017.

JOHANSON, Jan \& VAHLNE, Jan-Erik. (1977), "The internationalization process of the firm:- a model of knowledge development and increasing foreign market commitments". Journal of International Business Studies, 8: 23-31.

JOHANSON, Jan \& WIEDERSHEIM-PAUL, Finn. (1975), "The internationalization of the 
Firm-Four Swedish cases". Journal of Management Studies, 12 (3): 305-322.

JOHNSON, Jeffrey. (2004), "Factors influencing the early internationalization of high technology start-ups: US and UK evidence". Journal of International Entrepreneurship, 2: 139-154.

KUEMMERLE, Walter. (2005), "The entrepreneur's path to global expansion”. MIT Sloan Management Review, 46: 42-49.

MCDOUGALL, Patricia \& OVIATT, Benjamin. (2003), "Defining international entrepreneurship and modeling the speed of internationalization". Entrepreneurship Theory \& Practice, 29 (5): 537-554.

MCDOUGALL, Patricia; SHANE, Scott \& OVIATT, Benjamin. (1994), "Explaining the formation of international new ventures: the limits of theories from international business research". Journal of Business Venturing, 9 (6): 469-487.

MARTINELLI, A. (2009), "O contexto do empreendedorismo", in A. C. B. Martes (org.), Redes e sociologia econômica, São Carlos (SP), Edufscar.

MECKL, Reinhard \& SCHRAMM, Robert. (2005), "Empirical evidence for a theory of international new ventures". Arbeits- und Diskussionspapiereder Wirtschaftswissenschaftlichen Fakultät der Friedrich-Schiller-Universität, 6. Disponível em: <http://citeseerx.ist. psu.edu/viewdoc/download; jsessionid=EE5D39049B070907854EC1BEF24966F8?doi=10.1.1.415.8088\&rep=rep1\&type $=$ pdf $>$. Acesso em: 23 out. 2017.

MORAIS, Jose Mauro. (2008), "Uma avaliação de programas de apoio financeiro à inovação tecnológica com base nos fundos setoriais e na lei de inovação", in J. De Negri e L. C. Kubota (orgs.), Políticas de incentivo à inovação tecnológica no Brasil, Brasília, Ipea.

NOGUEIRA, L. V. \& FERREIRA, R. T. (2017), Os impactos da abertura comercial e do investimento direto sobre o investimento doméstico. Estudos Econômicos, São Paulo, 47 (3): 531-557.

NORTH, D. C. et al. (2007), "Limited access orders in the developing world: a new approach to the problems of development”. World Bank. (World Bank Publications, n. 4359).
NUMELLA, N.; SAARENKETO, S. \& PUUMALAINEN, K. (2004), "A global mindset: a prerequisite for successful internationalization?”. Canadian Journal of Administrative Sciences, 21 (1): 51-64.

OECD - Organisation for Economic Co-Operation and Development. (2013), Technology and Industry Scoreboard 2013: innovation for growth. Disponível em: <http://www.oecd-ilibrary.org/ science-and-technology/oecd-science-technology-and-industry-scoreboard-2013_sti_scoreboard-2013-en>. Acesso em: 23 out. 2017.

OECD - Organisation for Economic Co-Operation and Development. (2014), OECD Science, Technology and Industry Outlook 2014. Disponível em: <http://ifuturo.org/documentacion/ Science\%20Technology\%20and\%20Industry\%20Outlook\%202014.pdf>. Acesso em: 23 out. 2017.

OVIATT, Benjamin \& MCDOUGALL, Patricia. (1994), "Toward a theory of international new ventures". Journal of International Business Studies, 25: 45-64.

OVIATT, Benjamin \& MCDOUGALL, Patricia. (1995), "Global start-ups: entrepreneurs on a worldwide stage". Academy of Management Executive, 9 (2): 30-43.

OVIATT, Benjamin \& MCDOUGALL, Patricia. (1999), "A framework for understanding accelerated international entrepreneurship". Research in Global Strategic Management, 7: 23-40.

OVIATT, Benjamin \& MCDOUGALL, Patricia. (2005), "Defining international entrepreneurship and modeling the speed of internationalization". Entrepreneurship Theory \& Practice, 29: 537-553.

RIALP, Alex et al. (2005), "The phenomenon of early internationalizing firms: what do we know after a decade (1993-2003) of scientific inquiry?”. International Business Review, 14: 147-166.

ROSSITER, Raissa. (2003), "Networks, collaboration and the internationalization of small and medium-sized enterprises: an interdisciplinary perspective on the network approach". School of Management. (Working Paper Bradford University, Part 1). 
RUZZIER, Mitja; HISRICH, Robert \& ANTONIC, Bostjan. (2006), "SME internationalization research: past, present and future". Journal of Small Business Enterprise Development, 13: 476-497.

SALMAN, Doaa M. (2014), "Determinants of entrepreneurs' activities: new evidence from cross-country data". Journal of International Commerce, Economics and Policy, 5 (3).

SAPIENZA, Harry et al. (2006), "A capabilities perspective on the effects of early internationalization on firm survival and growth". Academy of Management Review, 31 (4): 914-933.

SAXENIAN, Anna Lee \& SABEL, Charles. (2008), "Roepke lecture in Economic Geography Venture Capital in the 'Periphery': the new argonauts, global search, and local institution building". Economic Geography, 84: 379-394. Disponível em: <http://people.ischool.berkeley.edu/ anno/Papers/venture_capital_in_the_periphery.pdf>. Acesso em: 23 out. 2017.

SCIENCE \& Engineering Indicators 2016. Disponível em: <https://www.nsf.gov/statistics/2016/nsb20161/\#/>. Acesso em: 12 out. 2017.

TRIGUEIRO, Michelangelo Giotto. (2006), "As redes sócio-técnicas de biotecnologia”. Teoria \& Pesquisa, 1 (48). Disponível em: <http:// www.teoriaepesquisa.ufscar.br/index.php/tp/ article/viewFile/13/4>. Acesso em: 19 out. 2017.

TROILO, Michael. (2011), "Legal institutions and high-growth aspiration entrepreneurship". Economic Systems, 35: 158-175.

VIOTTI, Eduardo. (2008), "Brasil: de política de C\&T para política de inovação? Evolução e desafios das políticas brasileiras de ciência, tecnologia e inovação", in CGEE (Centro de Gestão e Estudos Estratégicos), Avaliação de políticas de ciência, tecnologia e inovação: diálogo entre experiências internacionais e brasileiras, Brasília, CGEE. Disponível em: <www.cgee.org.br/atividades $/$ redirect. php?idProduto $=5070>$. Aces so em: 16 out. 2017.

VOERMAN, Liane. (2003), The export performance of Europeans SMEs. Alblasserdam, Labirint Publ.
WEERAWARDENA, Jay. et al. (2007), "Conceptualizing accelerated internationalization in the born global firm: a dynamic capabilities perspective conceptualizing accelerated internationalization in the born". Journal of World Business, 42: 294306.

WHITTAKER, Andrew. (2009), Research skills for social work. Londres, Learning Matters.

ZAHRA, Shaker. (2005), "A theory of international new ventures: a decade of research". Journal of International Business Studies, 36: 20-28.

ZAHRA, Shaker \& GEORGE, Gerard. (2002), "International entrepreneurship: the current status of the field and future research agenda", in M. Hitt et al. (eds.), Strategic entrepreneurship, Oxford, Blackwell. 


\section{INTERNACIONALIZAÇÃO DE MICRO, PEQUENAS E MÉDIAS EMPRESAS INOVADORAS NO BRASIL: DESAFIOS DO NOVO PARADIGMA DE DESENVOLVIMENTO}

\author{
Sonia Karam Guimarães e Lucas \\ Rodrigues Azambuja
}

Palavras-chave: Brasil; Internacionalização; Empresas inovadoras; Empreendedorismo internacional; Novas tecnologias.

O artigo aborda o fenômeno internacionalização de micro, pequenas e médias empresas (MPMEs) inovadoras, no Brasil. O crescimento desse fenômeno, mundialmente, está relacionado a mudanças econômicas, científicas e tecnológicas que marcaram as últimas décadas do século XX, cuja dinâmica contribuiu para a emergência de um novo paradigma de desenvolvimento, em que a principal vantagem comparativa encontra-se no conhecimento e inovação, considerados o motor da economia. O estudo, de caráter exploratório e descritivo, baseou-se em pesquisa realizada no período 2012-2014, que investigou 60 empresas inovadoras localizadas nas cidades do Rio de Janeiro, São Paulo, Campinas, Porto Alegre e Florianópolis. Dentre as conclusóes do estudo, afirma-se que o ambiente econômico, social e cultural do país tende tanto a promover o processo de internacionalizaçáo dessas empresas - através de globalização, novas tecnologias e políticas públicas quanto a enfraquecê-lo - através de um ambiente fiscal desfavorável, burocracia excessiva, isolamento econômico-cultural, nível geral insatisfatório de educação e de qualificação dos recursos humanos, e instabilidade econômica. Algumas evidências sugerem que o ingresso na "nova economia" ocorre sem abandono de comportamentos e valores "tradicionais". Contudo, qualquer generalização seria precipitada dada a natureza da amostra, restrita e não aleatória.

\section{INTERNATIONALIZATION OF INNOVATIVE MICRO, SMALL AND MEDIUM FIRMS IN BRAZIL: CHALLENGES OF THE NEW DEVELOPMENT PARADIGM}

\author{
Sonia Karam Guimarães and Lucas \\ Rodrigues Azambuja
}

Keywords: Brazil; Internationalization; Innovative companies; International entrepreneurship; New technologies.

The article aims at discussing the phenomenon of internationalization of innovative micro, small and medium size firms in Brazil. The worldwide growth of this phenomenon is related to economic, scientific and technological changes that marked the twentieth century over the last few decades. The article is an exploratory and descriptive study based on research that surveyed 60 innovative companies located in the cities of Rio de Janeiro, São Paulo, Campinas, Porto Alegre and Florianópolis. The data collected suggest that the country's economic, social and cultural environment tends to favor these companies' internationalization process - through globalization, new technologies and public policies as well as to weaken them - through an unfavorable fiscal environment, excessive bureaucracy, economic and cultural isolation, low level of qualification of human resources and economic instability. However, any generalization would be hasty given the nature of the sample, restricted and not random.

\section{INTERNATIONALISATION DES MICROS, PETITES ET MOYENNES ENTREPRISES INNOVANTES AU BRÉSIL : DÉFIS DU NOUVEAU PARADIGME DE DÉVELOPPEMENT}

\author{
Sonia Karam Guimarães et Lucas \\ Rodrigues Azambuja
}

Mots-clés: Brésil; Internationalisation; Entreprises innovantes; Entrepreneuriat international; Nouvelles technologies.

L'article aborde le phénomène de l'internationalisation des micros, petites et moyennes entreprises (PME) innovantes au Brésil. La croissance de ce phénomène, dans le monde entier, est liée aux changements économiques, scientifiques et technologiques qui ont marqué les dernières décennies du XXème siècle, dont la dynamique a contribué à l'émergence d'un nouveau paradigme du développement dont le principal avantage comparatif réside dans la connaissance et l'innovation, considérés comme le moteur de l'économie. L'étude, de caractéristique exploratoire et descriptive, s'est fondée sur des recherches menées au cours de la période 2012-2014, au cours de laquelle ont été enquêtées 60 entreprises innovantes situés dans les villes de Rio de Janeiro, São Paulo, Campinas, Porto Alegre et Florianópolis. Parmi les conclusions de l'étude, nous affirmons que l'environnement économique, social et culturel du pays tend à la fois à promouvoir le processus d'internationalisation de ces entreprises - la mondialisation, les nouvelles technologies et les politiques publiques - quant à les affaiblir par un environnement fiscal défavorable, une bureaucratie excessive, un isolement économique et culturel, un faible niveau général d'éducation et de qualification des ressources humaines et une instabilité économique. Certaines données indiquent que l'entrée dans la "nouvelle économie " survient sans abandon des comportements et des valeurs " traditionnelles ". Cependant, toute généralisation serait hâtive étant donné la nature de l'échantillon, restrictive et non-aléatoire. 


\section{ERRATA}

RBCS vol.33 no 97/2018

DOI: $10.1590 / 339700 / 2018 \mathrm{ER}$

E-location: e339700ER

- Nos artigos: "O comitê de articulação federativa no governo Lula: os percalços da cooperação territorial"; "Marcuse crítico de Weber: a política no capitalismo tardio"; "Representação política: a virada construtivista e o paradoxo entre criação e autonomia"; "O pequeno investidor na bolsa brasileira: ascensão e queda de um agente econômico"; "Ciências humanas e neurociências: um confronto crítico a partir de um contexto educacional"; "A peculiaridade do maquiavelismo inglês: das origens ao século XVII"; "Internacionalização de micro, pequenas e médias empresas inovadoras no Brasil: desafios do novo paradigma de desenvolvimento"; "A luta pelo reconhecimento e o paradigma da dádiva: uma proposta de articulação teórica" e "Determinantes individuais e de contexto da simpatia partidária na América Latina", assim como nas resenhas: "Um acerto de contas com o judiciário argentino", "A imprevisibilidade democrática" e "Idle No More: sobre a mobilização indígena no Canadá", publicados na Revista Brasileira de Ciências Sociais, 2018, volume 33, número 97, cujos e-locations são respectivamente: e339703, e339704, e339705, e339710, e339702, e339706, e339708, e339709, e339711, e339715, e339716 e e339717, os prefixos do DOI estáo incorretos.

Onde se lia: "10.590"

Leia-se: "10.1590". 